\title{
Nippostrongylus brasiliensis infection in the rat: effect of iron and protein deficiency and dexamethasone on the efficacy of benzimidazole anthelmintics
}

\author{
V. M. DUNCOMBE, T. D. BOLIN, A. E. DAVIS, AND J. D. KELLY \\ From the University of New South Wales, Gastrointestinal Unit, Prince of Wales Hospital, Randwick, \\ and Department of Veterinary Pathology, University of Sydney, New South Wales, Australia
}

SUMMARY Malnutrition, anaemia, and gut parasites are commonly interrelated. Using the Nippostrongylus brasiliensis-rat model, the effect of iron and protein deficiency on the efficacy of benzimidazole anthelmintics was studied. It was demonstrated that the anthelmintics mebendazole and fenbendazole were significantly less effective in eradicating parasites when animals were deficient in iron and protein. This decreased efficacy of anthelmintics in iron and protein deficiency could not be overcome by intraperitoneal administration of the drug. Since nutritional deficiencies may act via impairment of the immune response, anthelmintic efficacy was determined in adequately nourished rats treated with the immunosuppressive drug dexamethasone. A similar decrease in efficacy of mebendazole was shown when these animals were treated with dexamethasone. Thus it is possible that lowered anthelmintic efficacy in iron and protein deficient animals is mediated by immune deficiency. These findings may be relevant to anthelmintic programmes in malnourished communities.

There is increasing evidence that nutritional deficiencies are associated with impairment of immune defence mechanisms in the host, and contribute to persistence or recurrence of infection (see review by Scrimshaw, 1975).

It has recently been shown that iron and protein deficiency potentiate helminth infections in an animal model (Bolin et al., 1977). Furthermore, it is recognised that certain parasites can induce deficiencies in infected hosts (reviewed by Symons, 1969). For example, the human hookworm Necator americanus can be associated with hypoproteinaemia and iron deficiency anaemia.

The effect on anthelmintic efficiency of nutrient imbalances induced by diet or parasites has not been investigated, although there are reports in the literature of reduced drug efficacy in severe helminth infections. For example, mebendazole is much less effective in heavy Trichuris trichiura infections in man (Peña Chavarria et al., 1973; Wolfe and Wershing, 1974). As severe trichuriasis is associated with anaemia and diarrhoea, this therapeutic failure

Received for publication 28 March 1977 with anthelmintics may be related to nutrient deficiencies.

The present experiment was designed to evaluate this hypothesis using the rat-Nippostrongylus brasiliensis model. In this system, experimental infection is produced by subcutaneous inoculation of infective larvae. These migrate to the lungs, up the trachea, and down the oesophagus to the small intestine where, six days after infection, they develop into mature worms. A complex multiphasic immune response is then mounted by the host which initiates expulsion of adult worms four days later (Kelly and Dineen, 1972; Kelly et al., 1973; Ogilvie and Jones, 1973; Kelly and Dineen, 1976). The animal then becomes resistant to re-infection, with less than $2 \%$ of a secondary challenge developing into mature worms (Africa, 1931; Love et al., 1974).

The mode of action of benzimidazole anthelmintics is not well understood. Recent work has suggested that they may have a selective biochemical action by inhibiting the fumarate reductase system in nematodes (Prichard, 1970). This pathway, exclusive to the parasite, is important in energy production from carbohydrate metabolism. It is not clear whether the drug is effective by absorption through 
the parasite cuticle or whether serum levels in the host are important in worm eradication.

\section{Methods}

PARASITE/ANIMALS

Methods for culture and inoculation of $N$. brasiliensis, estimation of worm burdens, and details of rat strains used have been described (Kelly and Dineen, 1972; Love et al., 1974).

\section{PREPARATION OF NUTRIENT DEFICIENT \\ ANIMALS}

A balanced synthetic diet was prepared for nutrient sufficient rats (Bolin et al., 1971). An iron and protein deficient diet was prepared by withdrawing iron from the diet and reducing the protein content from $30 \%$ to $10 \%$. The deficient animals were fed distilled water and housed in brass cages.

\section{ANTHELMINTICS}

Mebendazole ${ }^{1}$ (methyl-5(6)-benzoyle 1-2 benzimadazole carbamate) and fenbendazole ${ }^{2}$ (methyl 5(phenylthio)-2-benzimidazole carbamate) were obtained commercially. Recommended dose rates for these drugs are 12.5 and $5 \mathrm{mg} / \mathrm{kg}$, respectively.

\section{STATISTICS}

Analysis of variance was carried out on all data after transformation to $\log _{10}(x+1)$.

\section{Experimental design and results}

\section{EXPERIMENT 1}

\section{Effect of iron and protein deficiency on anthelmintic efficacy}

Six groups of Wistar strain rats were weaned onto synthetic diets at 4 weeks of age (Table 1). Groups 1 and 2 were fed a sufficient diet and groups 3 to 6 were fed an iron and protein deficient diet. After four weeks all animals were injected subcutaneously with 1000 infective larvae of $N$. brasiliensis. At the same time blood was collected for haemoglobin estimation, and deficient animals had a mean haemoglobin of $8.2 \pm 0.2 \mathrm{~g} / \mathrm{dl}$ and a mean body weight of 89 $\pm 4.1 \mathrm{~g}$, compared with a mean haemoglobin of $15.4 \pm 0.3 \mathrm{~g} / \mathrm{dl}$ and a mean weight of $213 \pm 6.7 \mathrm{~g}$ for sufficient animals.

Six days after inoculation four groups were treated with anthelmintics (mebendazole or fenbendazole) and two groups were left untreated. Thus one

${ }^{1}$ Telmin (Ethnor Pty. Ltd., 1-5 Khartoum Rd., Nth. Ryde, NSW, Australia).

${ }^{2}$ Panacur (Hoechst (Aust.) Ltd., 606 St. Kilda Rd., Melbourne, Vic., Australia). sufficient group and one deficient group were untreated and one sufficient group and one deficient group were treated with mebendazole at a dose rate of $25 \mathrm{mg} / \mathrm{kg}$. Of the remaining two groups one was treated with fenbendazole $(10 \mathrm{mg} / \mathrm{kg})$ and one was treated with mebendazole at 50 times the recommended dose $(625 \mathrm{mg} / \mathrm{kg})$. All animals were killed four days after treatment-that is, 10 days after infection-and total worm counts performed (Table 1).

Table 1 Anthelmintic efficacy of mebendazole and fenbendazole in iron and protein deficient rats infected with Nippostrongylus brasiliensis.

\begin{tabular}{|c|c|c|c|c|}
\hline $\begin{array}{l}\text { Group and } \\
\text { dietary iron } \\
\text { and } \\
\text { protein } \\
\text { status }\end{array}$ & $\begin{array}{l}\text { Treatment } \\
\text { Day } 6\end{array}$ & $\begin{array}{l}\begin{array}{l}\text { Dose } \\
\text { rate }\end{array} \\
(\mathrm{mg} / \mathrm{kg})\end{array}$ & $\begin{array}{l}\text { Total } \\
\text { worm count } \\
\text { (mean } \\
\text { value and } \\
\text { SE) } \\
\text { Day } 10\end{array}$ & P value \\
\hline $\begin{array}{l}\text { Sufficient } \\
1\end{array}$ & Nil & 一 & $358 \pm 43$ & Gp 2 × gp $3<0.01$ \\
\hline 2 & Mebendazole & 25 & $1 \pm 0$ & Gp 2 v gp $5<0.01$ \\
\hline $\begin{array}{l}\text { Deficient } \\
3\end{array}$ & Mebendazole & 25 & $69 \pm 21$ & \\
\hline 4 & Nil & 一 & $374 \pm 33$ & \\
\hline 5 & Fenbendazole & 10 & $187 \pm 32$ & \\
\hline 6 & Mebendazole & 625 & $0.75 \pm 0$ & \\
\hline
\end{tabular}

Mebendazole at a dose rate of $25 \mathrm{mg} / \mathrm{kg}$ administered by gastric intubation was very effective in eradicating parasites from animals on a sufficient diet, group 2 having a mean worm count of only 1 , representing an anthelmintic efficacy of greater than $99 \%$. In contrast, when the same dose of mebendazole was administered to iron and protein deficient animals a significant worm burden remained, the mean count for group 3 being $69 \pm 21$, an efficacy of approximately $80 \%$. Fenbendazole was even less effective with a mean worm burden of $187 \pm 32$, an efficacy of $50 \%$ (group 5). The difference in anthelmintic efficacy between deficient animals treated with either mebendazole (group 3) or fenbendazole (group 5) and sufficient animals (group 2) is significant at the $1 \%$ level.

When iron and protein deficient rats were treated with mebendazole at 50 times the normal dose ratethat is, $625 \mathrm{mg} / \mathrm{kg}$, group 6 - the parasites were effectively cleared, the mean remaining worm burden being less than 1 . In this group, however, all animals suffered from severe diarrhoea.

The mean worm burden in untreated animals from both sufficient (group 1) and deficient (group 4) groups was $358 \pm 43$ and $374 \pm 33$ respectively and this difference was not significant. 


\section{EXPERIMENT 2}

Effect of route of administration on anthelmintic efficacy in iron and protein deficiency

Although mebendazole and fenbendazole are insoluble some absorption from the gastrointestinal tract does occur (Prichard and Kelly, 1978). Despite the fact that the serum levels that are achieved are low these drugs are effective in eradicating parasites from sites outside the gastrointestinal tract such as the respiratory tract (Kelly et al., 1975).

Thus it was possible that malabsorption was responsible for the decreased anthelmintic efficacy in iron and protein deficient rats, as adult worms, normally confined to the upper jejunum, are located throughout the entire small intestine in deficient rats (Bolin et al., 1977).

This experiment was designed to evaluate the above hypothesis. Six groups of five animals were weaned onto a synthetic diet, with three groups on a sufficient diet (groups 1-3) and three groups on a deficient diet (groups 4-6). After four weeks all rats were inoculated with 1000 infective larvae of $N$. brasiliensis and haemoglobin levels performed. In addition, group 6 was pretreated with $5 \mathrm{mg}$ iron dextran ${ }^{3}$ intramuscularly two days before inoculation with larvae. The mean haemoglobin levels were $15 \cdot 3 \pm 0.3 \mathrm{~g} / \mathrm{dl}, 12 \cdot 1 \pm 0.3 \mathrm{~g} / \mathrm{dl}$, and $8.0 \pm 0.1 \mathrm{~g} / \mathrm{dl}$ for sufficient, replenished, and deficient groups respectively. Rats on a sufficient diet weighed 195 $\pm 13.8 \mathrm{~g}$ compared with $151 \pm 5.7 \mathrm{~g}$ for rats on a deficient diet.

Six days later all groups were treated with mebendazole at a dose rate of $12.5 \mathrm{mg} / \mathrm{kg}$ by either the intraperitoneal or intragastric route, except for group 1, which was left untreated and served as an infection control. All animals were killed four days after treatment and total worm counts performed. The results summarised in Table 2 show that intragastric mebendazole was significantly less effective in deficient animals (group 4, mean worm count $37 \pm 14$ ) compared with sufficient animals (group 2, mean worm count 0 ). Furthermore, intraperitoneal administration did not improve the efficacy of mebendazole in iron and protein deficiency, the mean worm count for group 5 being $33 \pm 7$. On the other hand, intraperitoneal mebendazole cleared all parasites in iron and protein sufficient animals, the mean worm count for group 3 being 0 .

In group 6, which was iron replenished, there was a marked improvement in drug effectiveness, the mean worm count being only $7 \pm 3$ compared with worm counts of 37 and 33 in non-repleted iron deficient animals (groups 4 and 5 respectively). There

${ }^{3}$ Imferon (Fisons Pty. Ltd., North Sydney, NSW, Australia).
Table 2 Anthelmintic efficacy of mebendazole in iron and protein deficient rats infected with Nippostrongylus brasiliensis: intraperitoneal and intragastric routes of administration compared.

\begin{tabular}{|c|c|c|c|c|}
\hline $\begin{array}{l}\text { Group } \\
\text { and } \\
\text { dietary } \\
\text { iron } \\
\text { and } \\
\text { protein } \\
\text { status }\end{array}$ & $\begin{array}{l}\text { Anthelmintic* } \\
\text { treatment } \\
\text { Day } 6\end{array}$ & $\begin{array}{l}\text { Route of } \\
\text { administration }\end{array}$ & $\begin{array}{l}\text { Total } \\
\text { worm } \\
\text { count } \\
\text { (mean } \\
\text { value and } \\
\text { SE) } \\
\text { Day } 10\end{array}$ & P value \\
\hline \multicolumn{5}{|c|}{ Sufficient } \\
\hline 1 & Nil & - & $366 \pm 33$ & Gp 2 v gp $4<0.01$ \\
\hline 2 & Mebendazole & Intragastric & 0 & Gp 6 v gp 2 NS $\ddagger$ \\
\hline 3 & Mebendazole & Intraperitoneal & $\mathbf{0}$ & Gp 4 v gp 5 NS \\
\hline \multicolumn{5}{|c|}{ Deficient } \\
\hline 4 & Mebendazole & Intragastric & $37 \pm 14$ & \\
\hline 5 & Mebendazole & Intraperitoneal & $33 \pm 7$ & \\
\hline $6+$ & Mebendazole & Intragastric & $7 \pm 3$ & \\
\hline
\end{tabular}

* Mebendazole was given at a dose rate of $12.5 \mathrm{mg} / \mathrm{kg}$.

$\dagger$ This group iron replenished two days before inoculation with $N$. brasilensis.

$\ddagger N S$ : not significant.

is no significant difference between anthelmintic efficacy in the iron replenished animals (group 6) and rats on a sufficient diet (group 2).

\section{EXPERIMENT 3}

Effect of dexamethasone on anthelmintic efficacy

Nutritionally induced iron and protein deficiency has been shown to affect both worm expulsion and anthelmintic efficacy. As delayed worm clearance is a result of impairment of the immune process governing expulsion (Bolin et al., 1977), it may be that immune deficiency also mediates decreased anthelmintic efficacy. This experiment was designed to evaluate the effect of steroid-induced immune deficiency on the chemotherapeutic activity of mebendazole.

Twenty adult Wistar rats fed a nutritionally sufficient commercial diet ${ }^{4}$ were divided into four equal groups. All were injected subcutaneously with 1000 infective larvae of $N$. brasiliensis. Animals in group 1 received no further treatment and acted as infection controls. On the day of inoculation, intramuscular injections of dexamethasone ${ }^{5}$ were started in groups 2 and 3 at a total dose rate of $0.4 \mathrm{mg} /$ animal daily (Ogilvie, 1965). Six days after infection groups 3 and 4 were treated with mebendazole at a dose rate of $12.5 \mathrm{mg} / \mathrm{kg}$, and total worm counts were performed on all animals four days later.

4Allied Feeds (42 Walker St., Rhodes, NSW, Australia). 'Decadron (Merck, Sharp \& Dohme (Aust. Pty. Ltd.), Granville, NSW, Australia). 
Table 3 Effect of dexamethasone on anthelmintic efficacy of mebendazole in rats infected with Nippostrongylus brasiliensis.

\begin{tabular}{llll}
\hline Group & Steroid* & $\begin{array}{l}\text { Anthelmintic } \\
\text { treatment }\end{array}$ & $\begin{array}{l}\text { Total worm P value } \\
\text { count (mean } \\
\text { value and }\end{array}$ \\
& Day 6 & $\begin{array}{l}\text { Day } 10 \\
\text { Dain } 10\end{array}$ \\
\hline 1 & Nil & Nil & $397 \pm 20.9 \quad$ Gp 3 v gp 4 < 0.05 \\
2 & $\begin{array}{l}\text { Dexa- } \\
\text { methasone }\end{array}$ & Nil & $442 \pm 32.7$ \\
3 & $\begin{array}{c}\text { Dexa- } \\
\text { methasone }\end{array}$ & Mebendazole & $229 \pm 32.0$ \\
4 & Nil & Mebendazole & $29 \pm 9.1$ \\
\hline
\end{tabular}

*Dexamethasone was given at a dose rate of $0.4 \mathrm{mg} /$ animal daily. † Mebendazole was given at a dose rate of $12.5 \mathrm{mg} / \mathrm{kg}$.

In the non-steroid treated rats, mebendazole was effective in clearing more than $90 \%$ of parasites (group 4, mean worm count $29 \pm 9 \cdot 1$ ), when compared with the infection control group (group 1, mean worm count $397 \pm 20.9$ ). In contrast, in steroid treated rats (group 3), mebendazole was only $50 \%$ effective in eradicating parasites, with a mean worm burden of $229 \pm 32$. This difference is significant at the $5 \%$ level. Worm counts in steroidtreated rats not given mebendazole (group 2, $442 \pm 32 \cdot 7$ worms) were not significantly different from the infection controls (group 1).

\section{Discussion}

These studies indicate that in the $N$. brasiliensis-rat model, iron and protein deficiency reduces the efficacy of the benzimidazole anthelmintics mebendazole and fenbendazole. This decreased efficacy can be overcome by the use of very large doses of mebendazole or by pretreating the rats with intramuscular iron. In addition, dexamethasone treatment reduces the efficacy of mebendazole in nutritionally sufficient rats.

The finding of decreased anthelmintic efficacy in iron and protein deficiency has not been demonstrated before. Mebendazole is a potent anthelmintic which is effective in man against trichuriasis (Miller et al., 1974), enterobiasis (Brugmans et al., 1971), ascariasis (Hutchison et al., 1975), and hookworm (Peña Chavarria et al., 1973). Furthermore, mebendazole is considered to be a notable advance in the treatment of trichuriasis as the first effective therapy without major side-effects (Archer, 1974). Thus, it is of interest that it is less effective in curing patients with severe trichuriasis (Peña Chavarria et al., 1973; Wolfe and Wershing, 1974). As severe infections are associated with chronic diarrhoea and anaemia, failures in treatment may be related to nutrient deficiencies.

It is possible that decreased anthelmintic efficacy in iron and protein deficiency is mediated by a defect in immune response. This concept is supported by the demonstration of reduced efficacy of mebendazole in dexamethasone-induced immunodeficient rats. Steroids, however, have a wide range of biological effects and a direct relationship between reduced anthelmintic efficacy and immune suppression remains to be demonstrated.

Hass (1973) investigated the effect of steroids on anthelmintic efficacy in this model. He postulated that in steroid-treated rats $N$. brasiliensis should be more susceptible to anthelmintics, but concluded that his results did not support this hypothesis. However, analysis of his figures shows that steroids, in fact, reduce the efficacy of several benzimidazole anthelmintics. For example, in his study, thiabendazole reduced parasite populations in steroid-treated rats by only $47 \%$, compared with $99 \%$ in control rats.

In the $N$. brasiliensis-rat model dietary induced iron and protein deficiency not only reduced anthelmintic efficacy, but also delayed worm expulsion (Bolin et al., 1977) and decreased acquired resistance to reinfection (Duncombe et al., unpublished).

There is evidence that an association exists between helminthiasis, malnutrition, and immunodeficiency states in man. Jose and Welch (1970) in a study on 2250 Aboriginal children found marked increases in total parasite load and number of species present in growth retarded compared with normal children. Cruz et al. (1966) and Rivera et al. (1970) have reported hyperinfection with Strongyloides stercoralis in a variety of immunodeficiency states, including steroid administration.

It therefore seems likely that dietary and/or parasite induced nutritional deficiency may play a role in potentiating gut parasites in man. Field studies using iron and protein supplementation are necessary to determine the validity of this concept.

We would like to thank Miss Glenda Walsh, Mr. Christopher Porter, and Mr. Ian Weston for their excellent technical assistance. This study was supported by a grant from the National Health and Medical Research Council.

\section{References}

Africa, C. M. (1931). Studies of the host relations of Nippostrongylus muris, with special reference to age resistance and acquired immunity. Journal of Parasitology, 18, 1-13.

Archer, J. D. (1974). A new anthelmintic (Editorial). Journal of the American Medical Association, 230, 1436. 
Bolin, T. D., McKern, A., and Davis, A. E. (1971). The effect of diet on lactase activity in the rat. Gastroenterology, 60, 432-437.

Bolin, T. D., Davis, A. E., Cummins, A. G., Duncombe, V. M., and Kelly, J. D. (1977). The effect of iron and protein deficiency on the expulsion of Nippostrongylus brasiliensis from the small intestine of the rat. Gut, 18, 182-186.

Brugmans, J. P., Thienpont, D. C., Van Wijngaarden, I., Vanparijs, O. F., Schuermans, V. L., and Lauwers, H. L. (1971). Mebendazole in enterobiasis. Radiochemical and pilot clinical study in 1,278 subjects. Journal of the American Medical Association, 217, 313-316.

Cruz, T., Reboucas, G., and Rocha, H. (1966). Fatal strongyloidiasis in patients receiving corticosteroids. New England Journal of Medicine, 275, 1093-1096.

Hass, D. K. (1973). Nippostrongylus brasiliensis: effect of dexamethasone upon anthelmintic efficacy. Experimental Parasitology, 33, 10-16.

Hutchison, J. G. P., Johnston, N. M., Plevey, M. V. P., Thangkhiew, I., and Aidney, C. (1975). Clinical trial of mebendazole, a broad spectrum anthelmintic. British Medical Journal, 2, 309-310.

Jose, D. G., and Welch, J. S. (1970). Growth retardation, anaemia and infection, with malabsorption and infestation of the bowel. Medical Journal of Australia, 1, 349-356.

Kelly, J. D., and Dineen, J. K. (1972). The cellular transfer of immunity to Nippostrongylus brasiliensis in inbred rats (Lewis strain). Immunology, 22, 199-210.

Kelly, J. D., Dineen, J. K., and Love, R. T. (1973). Expulsion of Nippostrongylus brasiliensis from the intestine of the rat: evidence for a third component in the rejection mechanism. International Archives of Allergy and Applied Immunology, 45, 767-779.

Kelly, J. D., Whitlock, H. V., Hogarth-Scott, R. S., and Mears, F. A. (1975). The anthelmintic efficacy of fenbendazole against a mixed nematode infection in sheep. Research in Veterinary Science, 19, 105-107.

Kelly, J. D., and Dineen, J. K. (1976). Prostaglandins in the gastrointestinal tract: evidence for a role in worm expulsion. Australian Veterinary Journal, 52, 391-397.
Love, R. J., Kelly, J. D., and Dineen, J. K. (1974). Nippostrongylus brasiliensis: effects of immunity on the preintestinal and intestinal larval stages of the parasite. International Journal for Parasitology, 4, 183-191.

Miller, M. J., Krupp, I. M., Little, M. D., and Santos, C. (1974). Mebendazole. An effective anthelmintic for trichuriasis and enterobiasis. Journal of the American Medical Association, 230, 1412-1414.

Ogilvie, B. M. (1965). The use of cortisone derivatives to inhibit resistance to Nippostrongylus brasiliensis and to study the fate of parasites in resistant hosts. Parasitology, 55, 723-730.

Ogilvie, B. M., and Jones, V. E. (1973). Immunity in the parasitic relationship between helminths and hosts. Progress in Allergy, 17, 93-144.

Peña Chavarria, A., Swartzwelder, J. C., Villarejos, V. M., and Zeledón, R. (1973). Mebendazole, an effective broad spectrum anthelmintic. American Journal of Tropical Medicine and Hygiene, 22, 592-595.

Prichard, R. K., and Kelly, J. D. (1978). The effect of benzimidazole resistance and route of administration on the uptake of fenbendazole and thiabendazole by Haemonchus contortus and Trichostrongylus colubriformis in sheep and on anthelmintic concentration in plasma. Veterinary Parasitology. (in press).

Prichard, R. K. (1970). Mode of action of the anthelmintic thiabendazole in Haemonchus contortus. Nature, 228, 684-685.

Rivera, E., Maldonado, N., Vélez-Garcia, E., Grillo, A. J., and Malaret, G. (1970). Hyperinfection syndrome with Strongyloides stercoralis. Annals of Internal Medicine, 72, 199-204.

Scrimshaw, N. S. (1975). Nutrition and infection. Progress in Food and Nutrition Science, 1, 393-420.

Symons, L. E. A. (1969). Pathology of gastrointestinal helminthiasis. International Review of Tropical Medicine, 3, 49-100.

Wolfe, M. S., and Wershing, J. M. (1974). Mebendazole. Treatment of trichuriasis and ascariasis in Bahamian children. Journal of the American Medical Association, 230, 1408-1411. 